\title{
RFID Positioning Robot: An Indoor Navigation System
}

\author{
Malothu Mohan \\ M.Tech(E.C.E) Student, M.R.E. College \\ mohannanda690@gmail.com
}

\author{
B.Sagar \\ Asst.Prof(E.C.E), M.R.E. College \\ boinapallysagar@gmail.com
}

\begin{abstract}
Short form of radio frequency identification also called as dedicated short range communication (DSRC) technology. RFID is used to explain many technologies that are used in radio waves for automatic identifications. RFID works as bar code identification systems however the difference between RFID and bar code technology is that RFID does not depends on the line-of-sight reading that bar code scanning requires to work. Radio-frequency identification makes use of an RFID, tag applied to a product, animal, or person for the purpose of identification and tracking by using radio waves. Almost all RFID tags have two parts. IC for storing and processing information and antenna for receiving and transmitting the wave. This mobile car unit system using RFID technology is supported by using ARM 7 based microcontroller.
\end{abstract}

Keywords: ARM7, LPC2148, RFID Reader, IR Sensor, RFID Tag, 16*2 LCD, DC Geared Motor, L293D, Kiel Development Tool, Flash magic software

\section{INTRODUCTION}

ARM7 (LPC2148) with 512 KB flash, 64 KB of Random Access Memory and several I/O devices. It has control commands like turn right, left speed up, down .It has to be written into the RFID tags beforehand and tags are then stuck on tracks. In this system we are interfaced IR sensor for obstacle detection. Whenever it detects any obstacle it will take the alternate path and moves to the forward direction.

RFID reader can be used to communicate with tags and sending the moving control instructions to Micro Controllable Unit, (MCU) devices. The Micro Controllable Unit module receives moving control commands and then controls mobile car. The proposed car has applications in payment systems, retailing, supply chain management, and manufacturing etc.

ARM/KEIL software can be used for developing the applications.LPC2148 development board also used for testing the built application sensors and wireless nodes are used to prove the complete setup.

\section{BLOCK DIAGRAM}

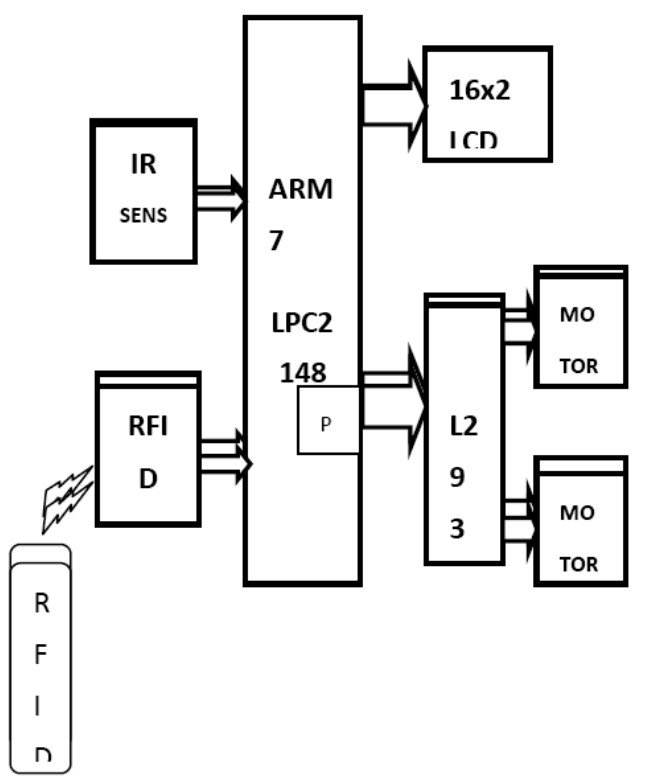

figure.1 


\section{MAIN CONCEPT}

The objective of project is to control the robot movement from remote areas, so wireless communication is used to fulfill our application. There are various wireless communications exist. For that we prefer RFID Module.

The purpose of system is to enable data to transmit signal with portable device, called a tag, which is received by an RFID reader and used according to the needs of a required application. The transmitted signal through tag may provide identification or location information of the product tagged, as price, color, of purchase date etc. This technology has been used by various companies for more than a decade.

The following technology gained attention because of its ability to track maneuver object.

\section{Algorithm}

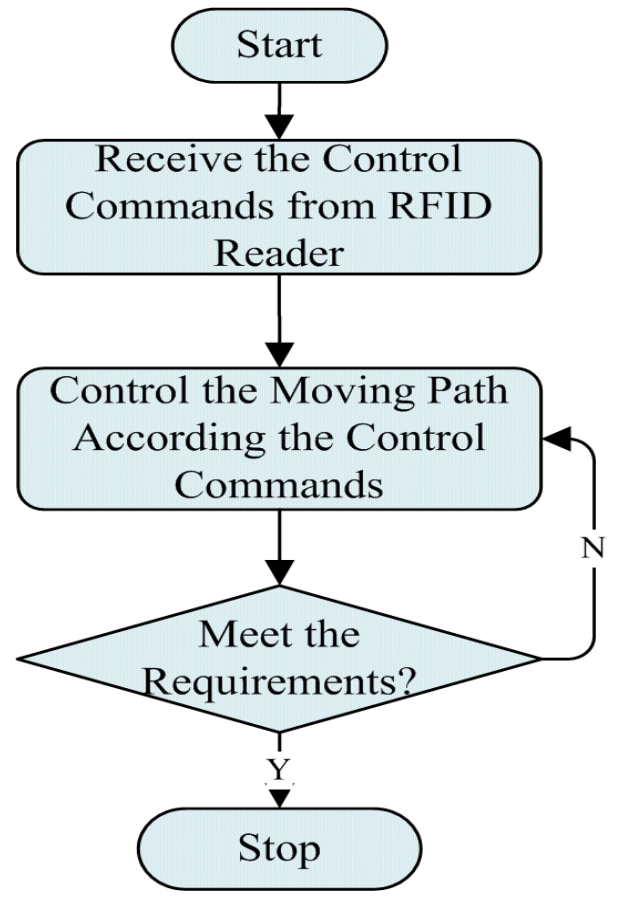

Figure2

\section{RFID}

Radio frequency identification is well known for dedicated short range communication technology. The module used by RFID is used to describe different technologies that use radio waves to identify people or objects. This identification technology is same as the bar-code recognition system, moreover only difference among RF identification and bar code system is RF identification do not depend on the line-of-sight receiving that bar code scanning process required to work.

RF identification system has three components:

- Antenna

- Transceiver (with decoder)

- Transponder (RF tag)
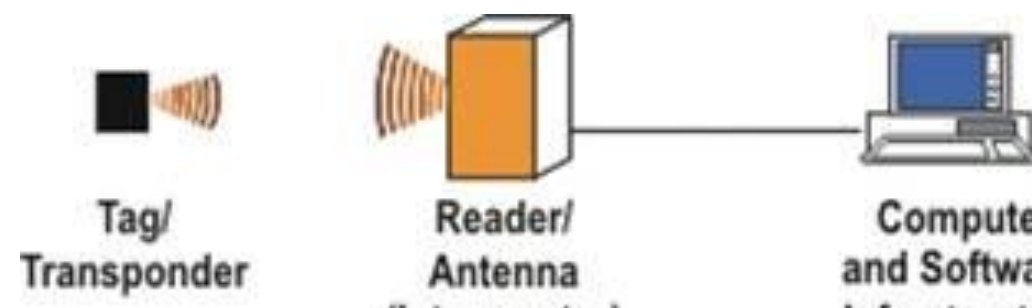

Reader/

Computer

Antenna

Figure.3 
- The provided antenna generates RF signals to activate the tag and to read and write information to it.

- The reader produce radio frequency waves in ranges between one inch to 100 feet or more, depending upon its power produced and the radio frequency used. As RFID tag passes through the electromagnetic zone, it detects the reader's activation signal.

- The reader decodes data encoded in the provided tag's integrated circuit (silicon chip) and then signal is passed on the host computer for processing of selected data.

- The purpose of system is to enable data to transmit signal with portable device, called a tag, which is received by an RFID reader and used according to the needs of a required application. The transmitted signal through tag may provide identification or location information of the product tagged, as price, color, of purchase date etc. This technology has been used by various companies for more than a decade.

- The following technology gained attention because of its ability to track maneuver objects. As the technology is far advanced even pervasive as well as invasive used technology

\section{IR SENSOR}

Infrared radiation is an electromagnetic spectrum having wavelengths higher than visible light wavelengths, but not greater than microwaves, i.e., from $0.75 \mu \mathrm{m}$ to $1000 \mu \mathrm{m}$ is the infrared region of range. Infrared waves are invisible to human. The wavelength provided between $0.75 \mu \mathrm{m}$ to $3 \mu \mathrm{m}$ is known near infrared, and region from $3 \mu \mathrm{m}$ to $6 \mu \mathrm{m}$ is called mid IR and the region more than $6 \mu \mathrm{m}$ is called far IR. (The demarcations are not rigid; regions are defined differently by many).

\section{Conclusion}

The design and development of RF identification based robot is successfully designed, fabricated and tested. With implementation of very low cost and flexibility in design, this kit can able reduce human introversion to greater extent. This project shows RF identification signal along with embedded system. This demonstration includes many examples provides how embedded system can make our life simple and stress free. This project includes robot that can be operated by RF identification tags, each and every tag is indicates such a direction. Its use is not limited to industries, with such modification the module can be applied to different purposes like in defense, coal mines and military applications etc.

\section{FUtURE SCOPE}

The main purpose of this project was to be able to create RFID MOBILE ROBOT.

RFID reader can collects the data from the tags and takes the direction.

- Extension of the project is we can interface GPS module can certainly be used to help with global navigation and for robot localization.

- Here we can interface the Camera to take the pictures with in a field and also interface one wireless communication module and send the data to the receiver part.

- The RFID tags can serve as a "sanity check" of sorts to check the work of the particle.

\section{REFERENCES}

[1] W. Gueaieb and M. S. Miah, "Experiments on a novel modular cost-effective RFID-based mobile robot navigation system," in Proceedings of the IEEE International Conference on Systems, Man, and Cybernetics, Montral, Canada, October 7-10 2007, pp. 1658-1663.

[2] J. Borenstein, H. R. Everett, L. Feng, and D. Wehe, "Mobile robot positioning: Sensors and techniques," Journal of Robotic Systems, vol. 14, no. 4, pp. 231-249, April 1997.

[3] L. R. Ojeda, G. D. Cruz, and J. Borenstein, "Currentbased slippage detection and odometry correction for mobile robots and planetary rovers," IEEE Transactions on Robotics, vol. 22, no. 2, pp. 366-378, April 2006.

[4] H. Makela and K. Koskinen, "Navigation of outdoor mobile robots using dead reckoning and visually detected landmarks," in Fifth International Conference on Advanced Robotics, 1991. 
[5] T. D'Orazio, M. Ianigro, E. Stella, F. P. Lovergine, and 94 JOURNALS OF COMMUNICATIONS, VOL. 4, NO. 2, MARCH 2009 @ 2009

A. Distante, "Mobile robot navigation by multi-sensory integration," in IEEE International Conference on Robotics and Automation, vol. 2, May 1993, pp. 373-379.

[6] S.-Y. Yi and B.-W. Choi, "Autonomous navigation of indoor mobile robots using a global ultrasonic system," Robotica Archive, vol. 22, no. 4, pp. 369-374, August

[7] 2004.

[8] Voorhoorst FA, Overbeeke KJ, Smets GJ. Using movement parallax for 3D laparoscopy. Med Prog Technol 1996; 21: 211-218.

[9] Becker H, Melzer A, Schurr MO, Buess G. 3-D video techniques in endoscopic surgery. Endosc Surg Allied Technol 1993; 1: 40 - 46.

[10] Van Bergen P, Kunert W, Bessell J, Buess GF. Comparative study of two-dimensional and threedimensional vision systems for minimally invasive surgery. Surg Endosc 1998; 12: 948-954.

[11] Birkett DH, Josephs LG, Este-McDonald J. A new 3-D laparoscope in gastrointestinal surgery. Surg Endosc 1994; 8: 1448-1451.

\section{AUTHOR's BIOGRAPHY}

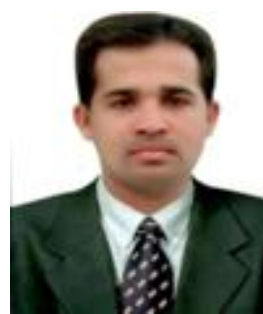

Malothu Mohan, Pursuing M.Tech in Embedded Systems from Malla reddy Engineering College [Autonomous], Mysammaguda, Hyderabad Telangana, India-500100. 